\title{
BMJ Open Primary care physicians' views on the factors for enhancing patients' trust in rural areas of Zhejiang province, China: a cross-sectional study
}

\author{
Jingjing Cai, ${ }^{1}$ Dan Wu (D) , ${ }^{2}$ Kai Sing Sun (D) , ${ }^{3,4}$ Shengzhi Yang, ${ }^{1}$ Kwok Fai Lam, ${ }^{5}$

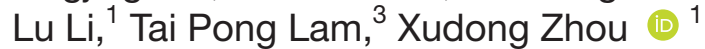

To cite: Cai J, Wu D, Sun KS, et al. Primary care physicians' views on the factors for enhancing patients' trust in rural areas of Zhejiang province, China: a crosssectional study. BMJ Open 2021;11:e049114. doi:10.1136/ bmjopen-2021-049114

- Prepublication history and supplemental material for this paper is available online. To view these files, please visit the journal online (http://dx.doi org/10.1136/bmjopen-2021049114).

Received 17 January 2021 Accepted 13 July 2021

Check for updates

(C) Author(s) (or their employer(s)) 2021. Re-use permitted under CC BY-NC. No commercial re-use. See rights and permissions. Published by BMJ.

For numbered affiliations see end of article.

Correspondence to Professor Xudong Zhou; zhouxudong@zju.edu.cn and Professor Tai Pong Lam; tplam@hku.hk

\section{ABSTRACT}

Objectives To examine primary care physicians' (PCPs) perception of patients' trust and associated factors for enhancing perceived trust in rural China.

Design A cross-sectional questionnaire study. Setting All township health centres (primary care facilities in rural areas of China) in both developed and less developed counties of Zhejiang province, China, were chosen as the study sites.

Participants A total of 849 questionnaires were distributed from December 2019 to January 2020, and 673 PCPs working in township health centres completed the questionnaires. The response rate was $79.3 \%$.

Outcome measures PCPs' perceived patients' trust in them, PCPs' practices to meet patients' expectations and PCPs' perceived conflicting patient and employer interests were measured by a self-designed and verified questionnaire. Confirmatory factor analysis was applied to verify the measurement model of PCPs' practices. Multivariable logistic regression analyses were performed to explore the association between clinical practice characteristics, discordant patient and employer interests and perceived patient trust after controlling for social-demographic characteristics.

Results Among all participants, 572 (85.0\%) PCPs often/ always perceived patients' trust in their clinical competence, and over two-thirds of PCPs reported ever perceived patient worries about overprescriptions. After adjustment for socialdemographic characteristics, regression model results indicated that, among PCPs' clinical practices characteristics, emotional support ( $\mathrm{OR}=1.23,95 \% \mathrm{Cl}=1.06$ to 1.42 ) and accurate diagnosis and treatment $(\mathrm{OR}=1.35,95 \% \mathrm{Cl}=1.17$ to 1.55) were positively associated with PCPs' perceived patients' trust in their clinical competence. A strong association was found between accurate diagnosis and treatment $(\mathrm{OR}=1.20$, $95 \% \mathrm{Cl}=1.08$ to $1.34, \mathrm{p}<0.001 ; \mathrm{OR}=1.22,95 \% \mathrm{Cl}=1.10$ to $1.35, p<0.001)$, conflicting patient and employer interests (OR=1.35, 95\% $\mathrm{Cl}=1.12$ to $1.63, \mathrm{p}<0.01 ; \mathrm{OR}=1.29,95 \%$ $\mathrm{Cl}=1.07$ to $1.54, \mathrm{p}<0.01)$ and PCPs' perceived patient worries about unnecessary medicine or tests, respectively. Conclusions PCPs' emotional support to patients as well as their abilities to make accurate diagnosis and provide appropriate treatment is positively associated with PCPs' selfreported patients' trust. It is recommended that reforms to realign patient and employer's interests be investigated.
Strengths and limitations of this study

- The measurement of perceived patients' trust was composed of patients' trust in PCPs' clinical competence and patients' worries about overprescriptions, which may supplement health service evaluation.

- Guided by the definition of trust and empathy role in clinical practices, emotional support was adopted to measure clinical practice characteristics, which may provide reference for future health service surveys.

- The rural setting of the study may compromise the representativeness of the sample.

- As the first study that shed lights on PCPs' perspective in patients' trust, patients were not included in this study, and further studies may need to look into trust from both PCPs' and patients' perspectives.

\section{INTRODUCTION}

A good patient-doctor relationship is key to providing quality primary care. To make it happen, patients' trust in primary care physicians (PCPs) is fundamental. ${ }^{1}$ Patients' trust has been frequently examined, ${ }^{1}$ and studies reported that it can be affected by individual, social and systematic factors. ${ }^{2-4}$ However, the reciprocal feature of this relationship is often neglected. PCPs' perceived patients' trust was a gratifying feature of general practice and is of high importance for enhancing physicians' morale. ${ }^{5}$ According to the Chinese National Health Service Survey, with the decline in medical personnel's self-perceived patients' trust and respect, from 2008 to 2013, their perception of patient satisfaction and professional sense of honour dropped by 5.8 percentage and 15.5 points, respectively. ${ }^{6}$ Recognition of patients' trust helps to build a rewarding doctor-patient relationship from physicians' perspective. ${ }^{5}$ Furthermore, how physicians evaluate patients' trust in themselves is recognised as imperative to build an efficient health system. ${ }^{7}$ PCPs' perception of 
patients' trust is therefore important to establish a wellfunctioning primary care system. ${ }^{8}$ Despite the significance, PCPs' self-perceived patients' trust in themselves is underexplored, both internationally and in China.

Since the beginning of the market-oriented economic reforms in the late 1970s, the elimination of social and economic basis of primary care system in rural areas has threatened the stability of primary care workforce. ${ }^{9}$ China has launched an ambitious health system reform since 2009, and one of its long-term strategies is to build a strong primary care system. ${ }^{10}$ As health resources in rural areas are limited compared with urban areas, ${ }^{8}$ township health centres are the main accessible and affordable source of care for rural residents. Thus, PCPs working in township health centres have received unprecedented attention. ${ }^{11}$ To enhance the primary care system by encouraging the gate-keeping role of PCPs, there is a need to improve PCPs' perception of patients' trust in rural China.

Patients' trust in PCPs in China has been frequently reported to have deteriorated in the past few decades, ${ }^{12}$ which may in turn affect PCPs' self-perceived patients' trust. A systematic review on the present profile of Chinese primary health workforce revealed that few rural PCPs felt high patients' trust in them. ${ }^{13}$ Patients' trust is commonly believed to be closely related to China's profit-oriented primary care system. ${ }^{14}$ During the barefoot doctor era when essential medical care was free, township health centres and village clinics provided first-contact primary care for the majority of rural citizens, while county and higher-level hospitals were responsible for providing subspecialty care. However, this three-tiered system has been malfunctioning since the market-oriented economic reforms. ${ }^{15}$ The dismantle of collective resident fundraising mechanism and reduction of governmental financial subsidies undermined financial stability of rural primary care system. Township health centres shifted from providing public health services to profitable health services in order to survive. ${ }^{9}$ PCPs working in township health centres were encouraged to generate revenue from diagnostic tests and medications. This led to widespread prescriptions of unnecessary tests and medicines, ${ }^{15}{ }^{16}$ leaving many patients feeling being exploited. Patient worries about PCPs' overprescribing behaviours and distrust in PCPs' professionalism are increasingly reported in the past decade. ${ }^{17}$ Furthermore, some PCPs felt pressured about making profit for the primary care facilities from unnecessary prescriptions and by compromising the benefits of patients, leading to a self-denial sentiment. ${ }^{14}$

Another key factor influencing PCPs' perceived patients' trust is their self-confidence in clinical competence. Earlier qualitative research indicated that Chinese PCPs seemed to have poor self-confidence in their clinical competence, and they also reported patient's distrust in their clinical capacity. ${ }^{18}$ Previous studies found that many Chinese residents preferred county or higher-level hospitals to primary care facilities even for minor health issues. ${ }^{10}{ }^{11}$ Some PCPs commented that patients perceive them as non-professional, which means that PCPs were only capable of providing a narrow range of low-quality healthcare services in patients' eyes. ${ }^{19}$ Such negative attitudes may discourage PCPs, harming their morale and enthusiasm to provide quality care..$^{20}$

Priorities have been given to primary care system throughout the world; especially in remote rural regions, PCPs received unprecedented attention. Although it is of great significance to have an insight of the patient-physician relationship from a mutual perspective, previous studies, in relation to patient-physician trust, focused on examining patients' attitudes. Earlier studies with Chinese PCPs examined job satisfaction and burnout, experience with patient violence and intention to quit. ${ }^{112}$ No published quantitative studies, however, are identified on Chinese PCPs' self-perceived patients' trust despite its importance. Only few qualitative studies found that there were five out of 12 rural physicians reporting patients' trust in them, suggesting the lack of large-scale empirical evidence in rural PCPs' perceived patients' trust. ${ }^{23}$ Our study aims to (1) examine PCPs' self-perceived patients' trust in rural areas of China and (2) explore potential factors that were related to PCPs' perceived patients' trust. In this study, both PCPs' perception of trust in clinical competence and prescribing behaviours were adopted to measure PCPs' perception of patients' trust, corresponding to the definition of physician-patient trust. ${ }^{24}$ Furthermore, previous studies claimed that trust was an anticipation of practices, so we hypothesised that there might be association between clinical practice characteristics, conflicting patient and employer interests and PCPs' perceived patients' trust.

\section{METHODS}

\section{Sampling and data collection}

We conducted a cross-sectional survey in rural areas of Zhejiang province, China, from December 2019 to January 2020. By the end of 2017, there were a total of 48009 primary healthcare workers, including 21134 PCPs in community-based health facilities in Zhejiang, which ranked third across the whole country. We defined developed and less developed areas according to gross domestic product (GDP) per capita of all counties using the 2018 census data of Zhejiang province. Those whose GDP per capita ranked in the top half were defined as developed areas, while those in the bottom half were defined as less developed areas.

In this study, the sample size required was calculated according to the sample size calculation formula of observational research. With limited evidence in PCPs' perceived patients' trust, we took the medical personnel's perception of patients' trust as an alternative. According to the 2013 Chinese National Health Service Survey, the proportion of medical personnel that perceived patients' trust in them was $53.5 \%{ }^{6}$; with a margin of error of 0.0535 at the $95 \%$ confidence level, a sample of size 348 is required. Considering a rejection and invalidity 
rate of $20 \%$, a minimum sample of size 435 is required. PCPs were recruited using a stratified cluster sampling method. We randomly selected two counties (Ning Hai and $\mathrm{Wu} \mathrm{Yi}$ ) in the developed areas and two counties (Pan An and Jiang Shan) in the less developed areas. All township health centres and affiliated units located within the four selected counties were included in this study. PCPs who were working in a township-based health centre or unit and holding a Chinese qualification for clinical practices certified by health authorities (referred as certified general practitioner) were invited to participate in this study. Those who were working in a secondary or tertiary hospital setting or temporarily working in a township health facility but holding a position in a higher-level care facility or serving as public health practitioners, nurses and technicians were excluded.

We collaborated with local health bureaus and a list of local township health facility directors, and contact details were provided by them. Our research staff reached out to facility directors and fully explained the research purpose and activities via telephone calls. We emphasised voluntary participation to directors, and refusal to participate would not affect interests of their facilities in any way. After obtaining approval from facility directors, we then invited eligible PCPs working on survey days. We provided informed consent form for PCPs, explained the research purpose and survey content and ensured potential participants' anonymity for the study. When informed consent was obtained, we invited PCPs to answer the questionnaire using an online questionnaire tool 'Sojump'.

\section{Questionnaire}

We developed our survey instrument based on our literature review and formative qualitative findings, and the questionnaire had been pretested in Zhejiang province. We measured PCPs' self-perceived patients' trust from two main aspects-clinical competence and worries about overprescriptions including medications and tests. Despite limited evidence from PCPs' perceived patients' trust in them, some studies have shown the mutual feature of physician-patient trust relationship that it refers to expectations of anticipated practices, ${ }^{25}$ which indicated the possible relationship between PCPs' practices to meet patients' expectations and PCPs' perceived patients' trust. A qualitative research conducted in rural China found that clinical treatment, clinical attitude and medical morality were recognised as three main factors, which may influence the establishment of physicianpatient trust from physicians' perspective. ${ }^{23}$ Consistent with empathy, theoretically and conceptually studied in the context of medical practice, emotional support, other than clinical treatment, provided by physicians with empathy is important to establish satisfied physician-patient relationship. ${ }^{26}$ Therefore, in our study, we adopted clinical practice characteristics, which could meet patients' expectations to see if there was association with PCPs' perceived trust. Regarding clinical practice characteristics, we evaluated from three dimensionsdiagnosis and treatment, explanation and elaboration and emotional support.

\section{PCPs' perceived patient trust}

According to the definition of physician-patient trust, ${ }^{25}$ the history of health reform in China and our previous studies, we measured PCPs' perceived patient trust from both perception of trust in medical services and PCPs' perception of patients' trust in their clinical competence (one item) and perception of trust in the maintenance of patients' interest and PCPs' perceived patient worries about overprescribing behaviours (two items). Questions were asked using a four-point Likert Scale. PCPs were invited to comment how often (1=seldom, 2=occasionally, $3=$ often and $4=$ always) they perceived patient trust in their clinical competence and how often they felt patient worries about unnecessary medicine or tests.

\section{Clinical practice characteristics}

A 10-item scale was used to assess PCPs' practices. With reference to our formative qualitative findings and Expectation Met Questionnaire (EMQ), ${ }^{27}$ a scale composed of three subscales, emotional support (four items), diagnosis and treatment (four items) and explanation and elaboration (two items), was constructed. Items were rated on a four-point Likert Scale from 1 'seldom' to 4 'always' to generate the total scores of three subscales. A higher score represents better quality of a certain domain of clinical practice and overall quality of clinical practices assessed in the study. Cronbach's $\alpha$ of the scale in this study was 0.887 . The result of confirmatory factor analysis (CFA) demonstrated a good construct validity of this scale (shown in online supplemental table 1 in appendix; $\mathrm{p}<0.001$; Normed fit index $(\mathrm{NFI})=0.936$; comparative fit index $(\mathrm{CFI})=0.943$; parsimony comparative fit index $(\mathrm{PCFI})=0.670)$.

\section{Conflicting patient and employer interests}

Conflicting patient and employer interests was measured by patient interest representation (one item) and perceived need for profit-making for their employer facility (one item). PCPs were asked to comment how often they put patients' interest first (reversely coded as $4=$ seldom, $3=$ occasionally, $2=$ often and $1=$ always) and how often they need to make revenue for medical institutions ( 1 =seldom, $2=$ occasionally, $3=$ often and $4=$ always $)$. A total score is generated by summing up both items. A higher score indicates more perception profit-making need.

\section{Social-demographic characteristics}

The social-demographic characteristics included gender, general practitioner qualification, practice year, education, annual income and geographical locations. On account of restrictive requirements for academic qualifications for the profession of physicians, educational attainment was dichotomised into 'postsecondary or less' and 'university or higher'. According to the average annual income in Chinese medical industry, PCPs were 
asked to comment whether their annual income was over 11814 (US\$) or not.

\section{Data analysis}

Descriptive analysis was conducted to observe socialdemographical characteristics of rural PCPs, perceived patient trust in rural PCPs and PCPs' practices to meet patients' expectations. CFA was applied to examine whether the relationship between a factor and the corresponding measurement item conforms to the theoretical relationship-EMQ. Multivariable logistic regression analyses with the forced entry method were performed to explore the association between clinical practice characteristics to meet patient expectations, discordant patient and employer interests and perceived patient trust by adjusting for the effects of the social-demographic characteristics. All analyses were performed using SPSS V.20.0 and AMOS V.25.0.

\section{Patient and public involvement}

No patients were involved in the design, recruitment and conduct of the study. The study participants and their faculties were offered feedback of the study results.

\section{RESULTS}

Among 849 invited, a total of 697 PCPs agreed to participate in this study, resulting in a response rate of $82.1 \%$. Duplicate participants were counted at the first time; then, the valid response rate was $79.3 \%(n=673)$. Table 1 presents social-demographic characteristics of our sample of rural PCPs. Overall, there were slightly more PCPs working in developed rural areas $(57.9 \%)$. And slightly more female physicians responded $(54.8 \%)$. Nearly twofifths of the respondents reported less than 10 years of experience. The majority of PCPs had obtained formal general practitioner qualification $(70.6 \%)$ and university level of education or above (71.2\%).

Table 2 summarises participants' responses to individual items related to PCPs' perceived patients' trust and clinical practice characteristics. Most PCPs (85\%) often/ always perceived patients' trust in their clinical competence. In the meantime, over two-thirds of PCPs reported perceived patient worries (including sometimes, often and always) about unnecessary medicine and test $(67.3 \%$ and $67.6 \%$, respectively). As to clinical practice characteristics, the mean score of the three subscales are 13.6, 8.3 and 6.3, respectively, in emotional support, diagnosis and treatment and explanation and elaboration. With regard to conflicting patient and employer interests, the mean score is 4.2 .

Table 3 shows the results of the multivariable logistic regression analyses. After adjustments of social-demographic factors, increase in emotional support scores $(\mathrm{OR}=1.23,95 \% \mathrm{CI}=1.06$ to $1.42, \mathrm{p}<0.01)$ and diagnosis and treatment scores $(\mathrm{OR}=1.35,95 \% \mathrm{CI}=1.17$ to 1.55 , $\mathrm{p}<0.001)$ were associated with higher perceived patients' trust in PCPs' clinical competence. After adjusting for
Table 1 Social-demographic factors of the sampled rural PCPs in Zhejiang province, China

\begin{tabular}{ll}
\hline & N (\%) \\
\hline Gender & $304(45.2)$ \\
Man & $369(54.8)$ \\
\hline Woman & \\
Certified general practitioner & $475(70.6)$ \\
\hline Yes & $198(29.4)$ \\
\hline No & \\
\hline Practice year & $262(38.9)$ \\
\hline $0-10$ & $192(28.5)$ \\
\hline $11-20$ & $219(32.5)$ \\
\hline$>20$ & $194(28.8)$ \\
\hline Educational attainment & $479(71.2)$ \\
\hline Postsecondary or less & \\
\hline University or higher & $340(50.5)$ \\
\hline Annual income (US\$) & $333(49.5)$ \\
\hline$\leq 11814$ (80 026 RMB) & \\
\hline$>11814$ (80 026 RMB) & \\
\hline Geographical locations & $225(33.4)$ \\
\hline Developed areas & $165(24.5)$ \\
\hline Ning Hai & \\
\hline Wu Yi & $201(29.9)$ \\
\hline Less developed areas & \\
\hline Jiang Shan & \\
\hline Pan An & \\
\hline
\end{tabular}

PCPs, primary care physicians; RMB, renminbi.

all social-demographic variables, respondents who scored higher in diagnosis and treatment $(\mathrm{OR}=1.20$, $95 \% \mathrm{CI}=1.08$ to $1.34, \mathrm{p}<0.001)$ reported more perceived patient worries about unnecessary medicine. In addition, those who reported higher level of conflicting patient and employer interests $(\mathrm{OR}=1.35,95 \% \mathrm{CI}=1.12$ to 1.63 , $\mathrm{p}<0.01)$ represented stronger need of profit-making and seldom put patients' interest first, also with more perception of patient worries about unnecessary medicine. The same association was shown between clinical practicing characteristics $(\mathrm{OR}=1.22,95 \% \mathrm{CI}=1.10$ to $1.35, \mathrm{p}<0.001)$, conflicting patient and employer interests $(\mathrm{OR}=1.29,95 \%$ $\mathrm{CI}=1.07$ to $1.54, \mathrm{p}<0.01)$ and perceived patient worries about unnecessary test.

\section{DISCUSSION}

China has given top priority to the transition from hospital-based to primary-care-centred health delivery system, especially in rural areas. ${ }^{11}$ In this context, the stability of primary care workforce assumes great significance. In order to improve PCPs' work morale, it is important to understand how PCPs perceive patients' trust 
Table 2 Perceived patients' trust, clinical practicing characteristics and conflicting patient and employer interests

\begin{tabular}{|c|c|}
\hline & $\mathbf{N}(\%)$ \\
\hline \multicolumn{2}{|l|}{ Perceived trust in clinical competence } \\
\hline Seldom & $12(1.8)$ \\
\hline Sometimes & $89(13.2)$ \\
\hline Often & $418(62.1)$ \\
\hline Always & $154(22.9)$ \\
\hline \multicolumn{2}{|l|}{ Worries about unnecessary medicine } \\
\hline Seldom & $220(32.7)$ \\
\hline Sometimes & $285(42.3)$ \\
\hline Often & 129 (19.2) \\
\hline Always & $39(5.8)$ \\
\hline \multicolumn{2}{|l|}{ Worries about unnecessary test } \\
\hline Seldom & $218(32.4)$ \\
\hline Sometimes & $274(40.7)$ \\
\hline Often & $137(20.4)$ \\
\hline Always & $44(6.5)$ \\
\hline Emotional support (total), mean (SD) & $13.6(2.3)$ \\
\hline \multicolumn{2}{|c|}{$\begin{array}{l}\text { I care about the psychological state of the } \\
\text { patient (such as their worries and mood) }\end{array}$} \\
\hline Seldom & $7(1.0)$ \\
\hline Sometimes & $64(9.5)$ \\
\hline Often & $377(56.0)$ \\
\hline Always & $225(33.4)$ \\
\hline \multicolumn{2}{|l|}{ I am polite to patients } \\
\hline Seldom & $5(0.7)$ \\
\hline Sometimes & $24(3.6)$ \\
\hline Often & $282(41.9)$ \\
\hline Always & $362(53.8)$ \\
\hline \multicolumn{2}{|c|}{$\begin{array}{l}\text { I have empathy for the patient (put myself in } \\
\text { the patients' situation) }\end{array}$} \\
\hline Seldom & $6(0.9)$ \\
\hline Sometimes & $29(4.3)$ \\
\hline Often & $306(45.5)$ \\
\hline Always & 332 (49.3) \\
\hline
\end{tabular}

I take care of the whole conditions of patients during consultation

\begin{tabular}{|c|c|}
\hline Seldom & $7(1.0)$ \\
\hline Sometimes & $31(4.6)$ \\
\hline Often & $312(46.4)$ \\
\hline Always & $323(48.0)$ \\
\hline Diagnosis and treatment (total), mean (SD) & $8.3(2.0)$ \\
\hline \multicolumn{2}{|l|}{$\begin{array}{l}\text { I believe my diagnosis and management } \\
\text { plans are up to date }\end{array}$} \\
\hline Seldom & $58(8.6)$ \\
\hline Sometimes & $225(33.4)$ \\
\hline
\end{tabular}

Continued
Table 2 Continued

\begin{tabular}{|c|c|}
\hline & N (\%) \\
\hline Often & 289 (42.9) \\
\hline Always & $101(15.0)$ \\
\hline \multicolumn{2}{|c|}{$\begin{array}{l}\text { I can differentiate most early-stage and } \\
\text { undiagnosed illnesses }\end{array}$} \\
\hline Seldom & $48(7.1)$ \\
\hline Sometimes & $206(30.6)$ \\
\hline Often & 332 (49.3) \\
\hline Always & $87(12.9)$ \\
\hline
\end{tabular}

I can correctly refer my patients when they need referral care professionally

Seldom

Sometimes $130(19.3)$

Often $398(59.1)$

Always

$134(19.9)$

Explanation and elaboration (total), mean (SD) 6.3 (1.3)

I will give patients plenty of time to explain their condition

\begin{tabular}{|cc|}
\hline \multicolumn{1}{|l|}{ Seldom } & $10(1.5)$ \\
\hline \multicolumn{1}{|c|}{ Sometimes } & $70(10.4)$ \\
\hline Often & $363(53.9)$ \\
\hline Always & $230(34.2)$ \\
\hline I have time to fully explain to the patient & \\
\hline Seldom & $11(1.6)$ \\
\hline Sometimes & $101(15.0)$ \\
\hline Often & $350(52.0)$ \\
\hline Always & $211(31.4)$ \\
\hline $\begin{array}{l}\text { Conflicting patient and employer interests } \\
\text { (total), mean (SD) }\end{array}$ & $4.2(1.1)$ \\
\hline I put the interests of patients first at work & \\
\hline Seldom & $8(1.2)$ \\
\hline Sometimes & $51(7.6)$ \\
\hline Often & $331(49.2)$ \\
\hline Always & $283(42.1)$ \\
\hline I need to consider how to make revenue for & \\
\hline medical institutions & \\
\hline Seldom & $112(16.6)$ \\
\hline Sometimes & $218(32.4)$ \\
\hline Often & $242(36.0)$ \\
\hline Always & $101(15.0)$ \\
\hline
\end{tabular}

seldom $=1$, sometimes $=2$, often $=3$ and always $=4$.

*This item was reversely coded.

in them and what factors may enhance PCPs' perception of patients' trust. ${ }^{5}$ This is the first study that looked into PCPs' perceived patient trust and its associated factors in rural China. We found that both accurate diagnosis and appropriate treatment and emotional support were 
Table 3 The association between PCPs' perceived patients' trust, clinical practicing characteristics and conflicting patient and employer interests

\begin{tabular}{|c|c|c|c|}
\hline & $\begin{array}{l}\text { Perceived trust in clinical } \\
\text { competence }(0=\text { seldom } \\
\text { and sometimes; } 1=0 \text { often } \\
\text { and always) OR }(95 \% \mathrm{Cl})\end{array}$ & $\begin{array}{l}\text { Worries about unnecessary } \\
\text { medicine }(0=\text { seldom and } \\
\text { sometimes; } 1=\text { often and } \\
\text { always) OR }(95 \% \mathrm{Cl})\end{array}$ & $\begin{array}{l}\text { Worries about } \\
\text { unnecessary test } \\
(0=\text { seldom and } \\
\text { sometimes; } 1=\text { often and } \\
\text { always) OR }(95 \% \mathrm{Cl})\end{array}$ \\
\hline \multicolumn{4}{|l|}{ Clinical practicing characteristics } \\
\hline Emotional support (continuous) & $1.23(1.06 \text { to } 1.42)^{\star \star}$ & 0.94 (0.83 to 1.06$)$ & 0.97 (0.86 to 1.09$)$ \\
\hline Diagnosis and treatment (continuous) & $1.35(1.17 \text { to } 1.55)^{\star \star \star}$ & $1.20(1.08 \text { to } 1.34)^{\star \star \star}$ & $1.22(1.10 \text { to } 1.35)^{\star \star \star}$ \\
\hline $\begin{array}{l}\text { Explanation and elaboration } \\
\text { (continuous) }\end{array}$ & 1.17 (0.90 to 1.53$)$ & $1.00(0.81$ to 1.23$)$ & 0.90 (0.74 to 1.10$)$ \\
\hline $\begin{array}{l}\text { Conflicting patient and employer } \\
\text { interests (continuous) }\end{array}$ & 0.83 (0.64 to 1.07$)$ & $1.35(1.12 \text { to } 1.63)^{\star \star}$ & $1.29(1.07 \text { to } 1.54)^{\star *}$ \\
\hline \multicolumn{4}{|l|}{ Certified general practitioner status } \\
\hline No & 1 & 1 & 1 \\
\hline Yes & $2.01(1.14 \text { to } 3.55)^{\star}$ & 0.96 (0.61 to 1.51$)$ & 0.94 (0.60 to 1.45$)$ \\
\hline \multicolumn{4}{|l|}{ Practice year } \\
\hline $0-10$ & 1 & 1 & 1 \\
\hline $11-20$ & 1.30 (0.69 to 2.42$)$ & 0.69 (0.43 to 1.12$)$ & 0.69 (0.43 to 1.10$)$ \\
\hline$\geq 21$ & $1.38(0.71$ to 2.71$)$ & $0.54(0.32 \text { to } 0.90)^{\star}$ & $0.56(0.34 \text { to } 0.93)^{\star}$ \\
\hline \multicolumn{4}{|l|}{ Gender } \\
\hline Man & 1 & 1 & 1 \\
\hline Woman & 0.86 (0.51 to 1.42$)$ & 0.75 (0.51 to 1.11$)$ & 0.84 (0.58 to 1.22$)$ \\
\hline \multicolumn{4}{|l|}{ Economic status of location } \\
\hline Less developed & 1 & 1 & 1 \\
\hline Developed & 0.89 (0.54 to 1.45$)$ & $1.32(0.89$ to 1.94$)$ & 1.13 (0.78 to 1.64$)$ \\
\hline \multicolumn{4}{|l|}{ Education } \\
\hline Postsecondary or less & 1 & 1 & 1 \\
\hline University or higher & 0.92 (0.54 to 1.56$)$ & 0.77 (0.51 to 1.16$)$ & 0.94 (0.62 to 1.42$)$ \\
\hline \multicolumn{4}{|l|}{ Income level (US\$) } \\
\hline$\leq 11814$ & 1 & 1 & 1 \\
\hline$>11814$ & 1.29 (0.78 to 2.13$)$ & 0.68 (0.46 to 1.01$)$ & 0.82 (0.56 to 1.20$)$ \\
\hline
\end{tabular}

${ }^{*} \mathrm{P}<0.05 ;{ }^{* *} \mathrm{p}<0.01 ;{ }^{* * *} \mathrm{p}<0.001$.

$\mathrm{PCPs}$, primary care physicians.

positively associated with PCPs' perceived patients' trust in their clinical competence. Moreover, we found a high level of perceived patients' worries about overprescriptions, and diagnosis and treatment, conflicting patient and employer interests, were associated factors.

First, provision of emotional support to patients was found to be positively associated with PCPs' perception of patients' trust in their clinical competence. This is consistent with previous research findings that emotional support was positively associated with patients' trust. ${ }^{28}$ This finding echoes the biopsychosocial model that highlights psychological support while managing patients in clinical care. ${ }^{5}$ Physicians' emotional support can benefit patients in several ways, which may lead to better patients' trust. ${ }^{20}$ Patients with better emotional support from their physicians had better adherence to medications and treatment effects. Patients were more likely to build partnership with physicians when they felt being cared. ${ }^{29}$ These can consequently make PCPs feel more respected, trusted and appreciated. ${ }^{29}{ }^{30}$ Our findings highlighted the need for mental health training in PCPs. Experiences in Hong Kong showed that mental health training module tailored for PCPs can improve their capacity to provide psychological care to patients. ${ }^{31}$ It may be worth considering to develop such training programmes as a strategy to improve rural PCPs' competence and self-value.

Despite high perceived patients' trust in clinical competence, over two-thirds of PCPs still reported sometimes/ often/always perceived patient worries about unnecessary medications or tests. These were much higher proportions compared with those of urban PCPs at $38.5 \%$ and $40.7 \%$, respectively. ${ }^{14}$ These are believed to be related 
to the widespread profit orientation of health facilities due to the reduction of public fiscal support, permission of $15 \%$ profit margins and fee-for-service payment system since the economic reforms. ${ }^{14-16}$ Our findings also revealed that PCPs who felt the need of profit-making and conflicting patient-employer interests were more likely to perceive patient worries about overprescriptions. It is highly recommended that government should invest more in government-owned township health centres, so that PCPs could focus on providing quality care other than making revenue for employer facilities.

Surprisingly, PCPs who reported more frequent accurate diagnosis and appropriate treatment were more likely to perceive patient worries about unnecessary medicine or test. We speculate that this might be because physicians with better performance may generally have a higher patient volume due to patient preference. ${ }^{11}$ This may consequently lead to two possibilities. First, such physicians may also be more likely to encounter patients with diverse economic backgrounds and those who have concerns about overprescriptions. ${ }^{32}{ }^{33}$ Second, in line with previous study, time pressure was closely related to prescriptions. ${ }^{34}$ With a larger average patient volume, the mean consultation time for each patient is likely shortened, causing more time pressure and insufficient communication about prescriptions. ${ }^{34}$ It may suggest that the process from appointment to consultation be optimised.

Trusted primary care workforce and primary care services are crucial to a well-functioning rural three-tiered healthcare system. This current study identified several ways for rural PCPs to take the initiative to improve primary care practices and gain patients' trust. In addition to improved professionalism, having empathy for patients and taking care of patients' emotions may contribute to high-level PCPs' perceived patients' trust and improve PCPs' morale. ${ }^{21}$

This study expands our knowledge of PCPs' perceived patients' trust and its associated factors in rural China. This research will serve as a foundation for future targeted interventions to improve PCPs' perceived trust, specifically in remote rural regions. However, several limitations to this study need to be acknowledged. First, the cross-sectional design limits our understanding of causal inference between PCPs' perceived patients' trust, their clinical practice characteristics and conflicting patient and employer interest. As the first study to explore associated factors with PCPs' perceived trust, our study findings shed lights on PCPs' perspective in the patientdoctor relationship. More work is however needed to better understand the mechanisms. Second, only rural PCPs in an economically better off eastern province were included in this study. It should be very cautious to extrapolate these results to other geographical areas, including both Chinese and international settings. Third, patients were not included in this study for evaluating their opinions towards PCPs' practices. Future studies may include patients as another angle to examine patients' trust and concerns in PCPs' professionalism and practices in rural China. Lastly, we adopted self-report measures in this study, and when it comes to clinical practice characteristics, PCPs may prefer to report positive feedback, which would lead to report bias. Although the interaction between physicians and patients was largely subjective and hard to quantify, future studies could consider surveying both physicians and patients to triangulate study findings.

\section{CONCLUSION}

This study highlighted the importance of patients' trust perceived by PCPs who should leverage the communitybased primary care setting to build a good doctor-patient relationship through, for example, taking care of patients' emotional well-being. Health authorities are encouraged to offer mental health training modules tailored for PCPs working in township health centres. The findings also suggest that more public funding should be invested in township health centres, so that PCPs could focus on providing quality care rather than making revenue.

\section{Author affiliations}

${ }^{1}$ The Institute of Social and Family Medicine, School of Medicine, Zhejiang University, Hangzhou, People's Republic of China

${ }^{2}$ International Diagnostic Centre, Clinical Research Department, London School of Hygiene \& Tropical Medicine, London, UK

${ }^{3}$ Department of Family Medicine and Primary Care, The University of Hong Kong, Hong Kong, People's Republic of China

${ }^{4}$ School of Public Health and Primary Care, The Chinese University of Hong Kong, Hong Kong, People's Republic of China

${ }^{5}$ Department of Statistics and Actuarial Science, The University of Hong Kong, Hong Kong, People's Republic of China

Acknowledgements The authors thank all participants in this study, as well as all the interviewers for data collection.

Contributors JC, DW, KSS, SY, TPL, LL and XZ conceived and designed the study. JC and SY collected the data. JC did the statistical analysis. KFL helped interpret the results and proposed precious advice. JC, DW and KSS drafted the manuscript. All authors have approved the final version of the manuscript for publication.

Funding This work was supported by the Academy of Medical Sciences and the Newton Fund (grant number NIFIR1\181020) and the Seed Fund for Basic Research, University Research Committee, the University of Hong Kong.

Competing interests None declared.

Patient consent for publication Not required.

Ethics approval Ethical approvals were obtained from the Institutional Review Board of the University of Hong Kong/Hospital Authority Hong Kong West Cluster (UW19-346) and Zhejiang University (ZGL201904-2).

Provenance and peer review Not commissioned; externally peer reviewed. Data availability statement № additional data are available.

Supplemental material This content has been supplied by the author(s). It has not been vetted by BMJ Publishing Group Limited (BMJ) and may not have been peer-reviewed. Any opinions or recommendations discussed are solely those of the author(s) and are not endorsed by BMJ. BMJ disclaims all liability and responsibility arising from any reliance placed on the content. Where the content includes any translated material, BMJ does not warrant the accuracy and reliability of the translations (including but not limited to local regulations, clinical guidelines, terminology, drug names and drug dosages), and is not responsible for any error and/or omissions arising from translation and adaptation or otherwise.

Open access This is an open access article distributed in accordance with the Creative Commons Attribution Non Commercial (CC BY-NC 4.0) license, which permits others to distribute, remix, adapt, build upon this work non-commercially, 
and license their derivative works on different terms, provided the original work is properly cited, appropriate credit is given, any changes made indicated, and the use is non-commercial. See: http://creativecommons.org/licenses/by-nc/4.0/.

\section{ORCID iDs}

Dan Wu http://orcid.org/0000-0003-0415-5467

Kai Sing Sun http://orcid.org/0000-0003-0631-9699

Xudong Zhou http://orcid.org/0000-0002-0784-5343

\section{REFERENCES}

1 Murray B, McCrone S. An integrative review of promoting trust in the patient-primary care provider relationship. J Adv Nurs 2015;71:3-23.

2 Carolyn T, Tim S, Richard B. Factors associated with patients trust in their general practitioner: a cross-sectional survey. Brit J Gen Pract 2003;53:798-800.

3 O'Malley AS, Sheppard VB, Schwartz M, et al. The role of trust in use of preventive services among low-income African-American women. Prev Med 2004;38:777-85.

4 Horn IB, Mitchell SJ, Wang J, et al. African-American parents' trust in their child's primary care provider. Acad Pediatr 2012;12:399-404.

5 Gronseth IM, Malterud K, Nilsen S. Why do doctors in Norway choose general practice and remain there? A qualitative study about motivational experiences. Scand J Prim Health Care 2020;38:184-91.

6 Wang H, Zhang YG, Xu L. Result 3 of the fifth National health service survey-the present situation of medical personnel practicing environment in China. Chinese $J$ Health Inform Manag 2014;11:321-5

7 Ozawa S, Sripad P. How do you measure trust in the health system? A systematic review of the literature. Soc Sci Med 2013;91:10-14.

8 Tao W, Zeng Z, Dang H, et al. Towards universal health coverage: lessons from 10 years of healthcare reform in China. BMJ Glob Health 2020;5:e2086

9 Wang H, Gusmano MK, Cao Q. An evaluation of the policy on community health organizations in China: will the priority of new healthcare reform in China be a success? Health Policy 2011;99:37-43.

$10 \mathrm{Ta} \mathrm{Y}$, Zhu Y, Fu H. Trends in access to health services, financial protection and satisfaction between 2010 and 2016: has China achieved the goals of its health system reform? Soc Sci Med 2020;245:112715.

11 WCM Y, Hsiao WC, Chen W. Early appraisal of China's huge and complex health-care reforms. Lancet 2012;379:833-42.

12 Duckett J, Hunt K, Munro N, et al. Does distrust in providers affect health-care utilization in China? Health Policy Plan 2016;31:1001-9.

13 Li H, Yuan B, Wang D, et al. Motivating factors on performance of primary care workers in China: a systematic review and metaanalysis. BMJ Open 2019;9:e28619.

14 Wu D, Lam TP, Lam KF, et al. Challenges to healthcare reform in China: profit-oriented medical practices, patients' choice of care and guanxi culture in Zhejiang Province. Health Policy Plan 2017;32:1241-7.

15 Blumenthal D, Hsiao W. Privatization and its discontents-the evolving Chinese health care system. N Engl J Med 2005;353:1165-70.
16 Babiarz KS, Miller G, Yi H, et al. China's new cooperative medical scheme improved finances of township health centers but not the number of patients served. Health Aff 2012;31:1065-74.

17 Lim M-K, Yang H, Zhang T, et al. Public perceptions of private health care in socialist China. Health Aff 2004;23:222-34.

18 Wu D. How to promote primary care in Zhejiang, China: a combined qualitative and quantitative study. PhD thesis. The University of Hong Kong 2017.

19 Feng D, Zhang D, Li B, et al. Does having a usual primary care provider reduce patient self-referrals in rural China's rural multi-tiered medical system? A retrospective study in Qianjiang district, China. BMC Health Serv Res 2017;17:778.

20 He W, Yuan X, Chen X. The relationship between patients' trust, medical explicit attitude and implicit attitude. Chinese $J$ Clin Psychol 2019;27:777-81.

21 Zhang L, Qiu Y, Zhang N, et al. How difficult doctor-patient relationships impair physicians' work engagement: the roles of prosocial motivation and problem-solving pondering. Psychol Rep 2020;123:885-902

22 Li H, Yuan B, Meng Q, et al. Contextual factors associated with burnout among Chinese primary care providers: a multilevel analysis. Int J Environ Res Public Health 2019;16 doi:10.3390/ijerph16193555

23 Liu Y, Wang XY, LM Y. Study of doctor-patient trust in township hospitals based on doctors' interview. Chinese Gen Pract 2014;17:4056-9.

24 Newcomer LN. Perspective: measures of trust in health care. Health Aff 1997;16:50-1.

25 Yang T, Wu Y. A study on the influence of patient participation on patient trust-based on sample survey in China. Front Psychol 2018;9:2189.

26 Linn LS, DiMatteo MR, Cope DW, et al. Measuring physicians' humanistic attitudes, values, and behaviors. Med Care 1987;25:504-15.

27 Williams S, Weinman J, Dale J, et al. Patient expectations: what do primary care patients want from the GP and how far does meeting expectations affect patient satisfaction? Fam Pract 1995;12:193-201.

28 Arora NK, Gustafson DH. Perceived helpfulness of physicians' communication behavior and breast cancer patients' level of trust over time. J Gen Intern Med 2009;24:252-5.

29 Dawson-Rose C, Cuca YP, Webel AR, et al. Building trust and relationships between patients and providers: an essential complement to health literacy in HIV care. J Assoc Nurses AIDS Care 2016;27:574-84.

30 Roter DL, Stewart M, Putnam SM, et al. Communication patterns of primary care physicians. JAMA 1997;277:350-6.

31 Lam TP, Sun KS, Piterman L, et al. Impact of training for general practitioners on their mental health services: the Hong Kong experience. Aust J Gen Pract 2018;47:550-5.

32 Yang J, Lv Z, Wang X. Comparative study on the doctor-patient trust level of urban and rural areas in Beijing (Chinese article). Chinese Hospital Manage 2015;35:44-7.

33 Liu H. On the patient feelings (Chinese article). Med Philosop 2017;38:6-10.

34 Liu C, Liu C, Wang D, et al. Intrinsic and external determinants of antibiotic prescribing: a multi-level path analysis of primary care prescriptions in Hubei, China. Antimicrob Resist Infect Control 2019;8:112-32. 